\title{
Common variants of the TLR9 gene influence the clinical course of $\mathrm{HBV}$ infection
}

\author{
NINA JIA, QING XIE, LANYI LIN, HONGLIAN GUI, HUI WANG, SHAN JIANG, HONG YU and QING GUO \\ Department of Infectious Disease, Ruijin Hospital, Shanghai Jiaotong University \\ School of Medicine, Shanghai 200025, P.R. China
}

Received September 23, 2008; Accepted November 13, 2008

DOI: 10.3892/mmr_00000096

\begin{abstract}
Hepatitis B virus (HBV) infection leads to the development of liver inflammation, causing morbidity and mortality. Multiple factors influence HBV progression, including genetic factors. Toll-like receptor (TLR)9 plays a key role in innate immunity, and mutations in the genes encoding this receptor have been associated with liver damage progression. Our study aimed to investigate one-tag single nucleotide polymorphisms (rs187084) representing the majority of common variations in TLR9 in a population-based study of Chinese patients. A total of 209 Chinese patients with HBV infection (130 with chronic hepatitis and 79 with liver cirrhosis) and 193 healthy individuals were studied. Our results showed that the frequencies of the $\mathrm{C} / \mathrm{C}$ genotype and $\mathrm{C}$ allele were statistically higher in patients with $\mathrm{HBV}$-related liver cirrhosis than in the healthy controls (26.6 vs. $15.5 \%$; $\mathrm{OR}=1.97,95 \%$ CI $1.05-3.71, \chi^{2}=4.483, \mathrm{P}=0.034 / 43.1$ vs. $37.8 \%$; OR=1.49, 95\% CI 1.02-2.16, $\left.\chi^{2}=4.323, \mathrm{P}=0.038\right)$. No significant differences in the frequencies of alleles or genotypes were found between patients with chronic hepatitis B and the control subjects. In conclusion, this study is the first to show that small effects within TLR9 contribute towards the development of HBV, supporting the hypothesis that little is currently known regarding the contribution of genetic factors to HBV.
\end{abstract}

\section{Introduction}

HBV infection leads to chronic liver inflammation in the majority of patients. A substantial proportion of patients develop fibrosis or cirrhosis, causing HBV-related morbidity and mortality. Multiple factors have an impact on the progression of chronic hepatitis B to cirrhosis, and its complications include gender, age, metabolic factors and alcohol consumption

Correspondence to: Dr Qing Xie, Department of Infectious Disease, Ruijin Hospital, Shanghai Jiaotong University School of Medicine, Shanghai 200025, P.R. China

E-mail: xieqingrj@yahoo.com.cn

Key words: hepatitis B virus, cirrhosis, toll-like receptor 9, single nucleotide polymorphisms, innate immunity
(1). In addition, genetic factors influence the progression of fibrosis. Angiotensin II, the main peptide of the reninangiotensin system, is involved in hepatic fibrosis through hepatic stellate cell activation $(2,3)$, while polymorphisms in the promoter region of the angiotensinogen gene have been shown to be associated with liver cirrhosis in patients with chronic hepatitis B (4). Cirrhosis results from the defective repair of liver damage resulting from inflammation caused by the effector cells of the immune system. Cytokine interferon (IFN)- $\alpha$ is a key mediator at the interface between innate and adaptive immunity. It is mainly produced by plasmacytoid dendritic cells (pDCs) after the engagement of toll-like receptors (TLRs) $(5,6)$. TLR9 is promising as an immune mediator candidate in HBV infection since it is expressed in pDCs, binds cytidine-phosphate-guanosine (CpG) DNA motifs that are present in viruses, and stimulates the secretion of interferon- $\alpha(5,6)$ when activated. There is evidence to support a role for TLR9 in HBV infection, in that a clinical study demonstrated an antiviral effect of the TLR9 agonist CpG ODN, which was able to significantly inhibit HBV replication in vitro (7). The low expression of TLR9 mRNA was also recently detected in the peripheral blood mononuclear cells of chronic hepatitis B patients (8). TLR9 may therefore be a potential candidate gene contributing to HBV development or influencing the clinical course of the disease. Despite a plausible role for TLR9 in the development of HBV infection, to our knowledge no previous study has been conducted to investigate whether a common variation in the TLR9 gene is involved in $\mathrm{HBV}$ aetiology. We aimed to examine this issue by selecting tag single nucleotide polymorphisms (SNPs) that predicted at least $90 \%$ of the entire common variation in this gene. We then assessed the association between these SNPs and HBV infection by means of a population-based study of Chinese patients.

\section{Materials and methods}

Study population. Two hundred and nine HBV-infected patients were enrolled at Ruijin Hospital, Shanghai Jiaotong University School of Medicine. Patients were positive for HBsAg but negative for anti-HCV and -HIV. As a control group, 193 healthy blood donors were analysed. None of the subjects had a history of alcohol or drug abuse. Patients did not receive antiviral or immunosuppressive therapy prior to or during the course of the study. The HBV-infected patients were categorised into two groups according to diagnosis 
Table I. Clinical patient characteristics.

\begin{tabular}{lccc}
\hline Characteristics & NC $(\mathrm{n}=193)$ & CHB $(\mathrm{n}=130)$ & LC $(\mathrm{n}=79)$ \\
\hline Sex (M/F) & $120 / 73$ & $105 / 65$ & $65 / 14$ \\
Age (years) & 42 & 44 & 50 \\
ALT (n.v. 10-60 IU/l) $)^{\mathrm{a}}$ & $24(19-37)$ & $405(16-1369)$ & $160(14-1262)$ \\
AST (n.v. 10-42 IU/l) & $21(14-38)$ & $192(16-845)$ & $158(25-1607)$ \\
TB (n.v. 3.4-24.0 $\mu \mathrm{mol} / \mathrm{l})^{\mathrm{a}}$ & $17(4.6-20)$ & $84(5.3-511)$ & $150(10.3-650)$ \\
DB (n.v. 0-6.8 $\mu \mathrm{mol} / \mathrm{l})^{\mathrm{a}}$ & $3.2(1.4-4.8)$ & $45(1.3-266)$ & $75(2.6-315)$ \\
PT (n.v. 13 $\pm 3 \mathrm{sec})$ & $11(10-13)^{\mathrm{d}}$ & $13(11-15)^{\mathrm{c}}$ & $21(12-36)^{\mathrm{b}}$ \\
\hline
\end{tabular}

${ }^{a}$ Median (inter-quartile range). $\mathrm{P}<0.01$ for comparison with all other groups; ${ }^{\mathrm{b}} \mathrm{vs} .{ }^{\mathrm{c}}, \mathrm{P}<0.01 ;{ }^{\mathrm{b}} \mathrm{vs} .{ }^{\mathrm{d}}, \mathrm{P}<0.01$. n.v., Normal values. NC, normal control; CHB, chronic hepatitis B; LC, liver cirrhosis; ALT, alanine aminotransferase; AST, aspartate aminotransferase; IU, international units; $\mathrm{TB}$, total bilirubin; $\mathrm{DB}$, direct bilirubin; $\mathrm{PT}$, prothrombin time.

(Table I). The groups were well-characterised, with patients exhibiting symptoms such as chronic hepatitis $B(n=130)$ and liver cirrhosis $(n=79)$. Classification of the groups was based on chronic viral hepatitis B-fatigue, anorexia, jaundice, hepatomegaly, splenomegaly, hyperbilirubinemia, increased serum alanine aminotransferase (ALT) and aspartate aminotransferase (AST), and positivity for $\mathrm{HBsAg}$ for $>6$ months. Patients with liver cirrhosis had a history of HBV infection. At the time of the study, the symptoms observed were: anorexia, nausea, vomiting, malaise, weight loss, abdominal distress, jaundice, oedema, cutaneous arterial 'spider' angiomas, palma erythrema, ascites, shrunken liver, splenomegaly, mild or pronounced hyperbilirubinemia, elevated levels of serum ALT and AST and decreased serum albumin levels, along with increased serum globulins, an albumin/globulin (A/G) rate $<1$, and positivity for HBsAg. For the healthy controls, blood was collected from 193 blood donors. These individuals were confirmed to be negative for HBsAg, anti-HCV and -HIV by routine serology. Oral and written informed consent from the participating subjects was obtained prior to obtaining patient peripheral blood samples.

Detection of hepatitis B virus antigens and antibodies. Serum $\mathrm{HBsAg}, \mathrm{HBeAg}$, anti-HBs, anti-HBe and anti-HBc were assayed by ELISA kits (BioKit, Spain), according to the manufacturer's instructions.

Selection of single nucleotide polymorphisms. For SNP selection, Haploview software (http://www.broad.mit.edu/ $\mathrm{mpg}$ /haploview) was used to conduct linkage disequilibrium using Hapmap phase genotype data for chromosomal region 3: 52,230,137-52,235,218 (chronic hepatitis B database, Hapmap release 21a, January 2007). The amplicon of interest is a $5.082-\mathrm{kb}$ region encompassing the domain $\sim 3 \mathrm{~kb}$ upstream and $3 \mathrm{~kb}$ downstream of TLR9. TagSNP selection was performed by running the tagger program implemented in Haploview. The criteria for $\mathrm{r}^{2}$ were set at $>0.8$, meaning that any marker that was not eventually selected as a tagging marker was already strongly correlated with at least one of the tagging markers with $r^{2}>0.8$. One-tag SNP (rs187084) within TLR9 was examined in 209 patients, including 130 with chronic HB and 79 with HBV-related liver cirrhosis, as well as in 193 healthy controls.
Genotype analysis. Genomic DNA was extracted from peripheral blood mononuclear cells using a commercially available kit (Qiagen, Hilden, Germany) according to the manufacturer's instructions. Polymorphisms of T-1486C (rs187084) in the TLR9 gene were detected by PCR restriction fragment length polymorphism analysis. A 356 base-pair fragment containing the polymorphic site was amplified using TLR9-specific primers (forward 5'-CATTCATTCAGCCTTCACTCA-3'; reverse 5'-TGACATGGGAGCAGAGACATA-3'). PCR was performed using a mixture containing $1.5 \mathrm{mM} \mathrm{MgCl} 2,10 \mathrm{mM}$ dNTP, 50 ng genomic DNA, $20 \mu \mathrm{mol}$ of each primer and $2.5 \mathrm{U}$ Taq DNA polymerase (Sangon, Shanghai, P.R. China) at a volume of $50 \mu \mathrm{l}$. Amplification was performed for 30 cycles with preheating at $95^{\circ} \mathrm{C}$ for $3 \mathrm{~min}$, followed by denaturation at $94^{\circ} \mathrm{C}$ for $30 \mathrm{sec}$, annealing at $58^{\circ} \mathrm{C}$ for $40 \mathrm{sec}$ and extension at $72^{\circ} \mathrm{C}$ for $45 \mathrm{sec}$. The PCR product was incubated with the restriction enzyme Afl for $2 \mathrm{~h}$ at $37^{\circ} \mathrm{C}$, and the digestion products were resolved on a $3 \%$ agarose gel stained with ethidium bromide.

Statistical analysis. Distribution of alleles and genotypes among the studied groups was analysed by the $\chi^{2}$ test for $2 \times 2$ or $2 \times 3$ tables. Statistical significance was defined as $\mathrm{P}<0.05$. Deviation from the Hardy-Weinberg equilibrium was tested using the Pearson $\chi^{2}$ test statistic (SPSS software version 11.5, SPSS Inc., Chicago, IL, USA).

\section{Results}

Clinical symptoms and liver parameters of hepatitis $B$ virusinfected patients. In total, $209 \mathrm{HBV}$-infected individuals with well-characterised clinical profiles, including different forms of hepatic disease (chronic hepatitis and liver cirrhosis), were enrolled. Clinical details and the results of biochemical analysis from the different patient groups at the time of the study are shown in Table I.

In accordance with other studies, we observed that prothrombin time was significantly longer in patients with liver cirrhosis than in other groups $(\mathrm{P}<0.01)$. The AST/ALT ratio increased significantly from chronic hepatitis B to liver cirrhosis $(\mathrm{P}<0.01)$ patients, indicating a positive correlation with liver function impairment and progressively severe pathological processes. 
Table II. Genotype distributions and allele frequencies of TLR9 polymorphisms in patients with chronic hepatitis B (CHB) and normal controls (NC).

\begin{tabular}{|c|c|c|c|c|c|}
\hline & $\begin{array}{c}\mathrm{NC} \\
\text { No. }(\%)\end{array}$ & $\begin{array}{c}\text { CHB } \\
\text { No. }(\%)\end{array}$ & $\chi^{2}$-value & OR $(95 \% \mathrm{CI})$ & P-value \\
\hline \multicolumn{6}{|l|}{ Allele } \\
\hline $\mathrm{T}$ & $240(62.2)$ & $152(58.5)$ & 0.898 & $1.17(0.85-1.61)$ & 0.343 \\
\hline C & $146(37.8)$ & $108(41.5)$ & & & \\
\hline Total & $386(100)$ & $260(100)$ & & & \\
\hline \multicolumn{6}{|c|}{ Genotype } \\
\hline $\mathrm{TT}$ & 77 (39.9) & 48 (36.9) & 1.076 & $\mathrm{TT}+\mathrm{TC}$ vs. CC & 0.3 \\
\hline $\mathrm{TC}$ & $86(44.6)$ & $56(43.1)$ & & $1.36(0.76-2.43)$ & \\
\hline $\mathrm{CC}$ & $30(15.5)$ & $26(20.0)$ & & & \\
\hline Total & $193(100)$ & $130(100)$ & & & \\
\hline
\end{tabular}

Table III. Genotype distributions and allele frequencies of TLR9 polymorphisms in patients with liver cirrhosis (LC) and normal controls (NC).

\begin{tabular}{|c|c|c|c|c|c|}
\hline & $\begin{array}{c}\text { NC } \\
\text { No. }(\%)\end{array}$ & $\begin{array}{c}\text { CHB } \\
\text { No. }(\%)\end{array}$ & $\chi^{2}$-value & OR $(95 \% \mathrm{CI})$ & P-value \\
\hline \multicolumn{6}{|l|}{ Allele } \\
\hline $\mathrm{T}$ & $240(62.2)$ & $83(56.9)$ & 4.323 & $1.49(1.02-2.16)$ & 0.038 \\
\hline $\mathrm{C}$ & $146(37.8)$ & 75 (43.1) & & & \\
\hline Total & $386(100)$ & $158(100)$ & & & \\
\hline \multicolumn{6}{|c|}{ Genotype } \\
\hline $\mathrm{TT}$ & 77 (39.9) & $25(31.6)$ & 4.483 & $\mathrm{TT}+\mathrm{TC}$ vs. CC & 0.034 \\
\hline $\mathrm{TC}$ & $86(44.6)$ & $33(41.8)$ & & $1.97(1.05-3.71)$ & \\
\hline $\mathrm{CC}$ & $30(15.5)$ & $21(26.6)$ & & & \\
\hline Total & $193(100)$ & 79 (100) & & & \\
\hline
\end{tabular}

Association between the TLR9 polymorphism and hepatitis $B$ virus infection. Genotype frequencies of patients and control subjects were compatible with the Hardy-Weinberg law. Frequencies of the $\mathrm{C} / \mathrm{C}$ genotype and $\mathrm{C}$ allele were higher in patients with HBV-related liver cirrhosis than in the healthy controls (26.6 vs. $15.5 \%$; OR $=1.97,95 \%$ CI $1.05-3.71$, $\chi^{2}=4.483, \mathrm{P}=0.034 / 43.1$ vs. $37.8 \% ; \mathrm{OR}=1.49,95 \% \mathrm{CI}$ 1.02-2.16, $\chi^{2}=4.323, \mathrm{P}=0.038$ ) (Table III). No significant differences in the frequencies of alleles or genotypes were found between the chronic hepatitis B patients and the control subjects (Table II).

Association between the TLR9 polymorphism and gender. Regulation of innate immune response is gender-dependent, 43-45 in the present study. A comparative study of the TLR9 polymorphism in males and females was also conducted, but no statistical differences were found in the comparison of the frequencies of alleles or genotypes with gender composition.

\section{Discussion}

It is well known that HBV elimination by the infected host is attributable to a coordinated innate and adaptive humoral and cell-mediated immune response. TLR genes encode a family of transmembrane proteins that play an essential role in the activation and regulation of innate and adaptive immunity through their recognition of specific molecular patterns of pathogens (6). SNPs of other TLRs influence the efficacy of immune response in bacterial, viral and parasite infections. TLR2 binds lipoproteins, and its polymorphisms have been implicated in Borrelia burgdorferi infection as well as in tuberculosis and leprosy $(9,10)$. TLR4 binds lipopolysaccharide, and its polymorphisms influence the course of disease in meningococcal infection (11), candidiasis (12), gram-negative bacteremia (13-15) and respiratory syncytial virus (16). Polymorphisms of the gene of flagellin-binding TLR5 are associated with susceptibility to Legionnaires' disease (17). TLR7 binds single-stranded RNA, and its polymorphisms have been implicated in HCV infection (18). Although TLR7 stimulation shows antiviral effects in HBV infection (18), TLR7 binding has only been demonstrated for RNA viruses (6), and the binding of HBV to TLR7 is unlikely. TLR9 is engaged by unmethylated CpG-rich DNA, common in bacteria and also prevalent in the genomes of DNA viruses, then triggers a cascade of events that lead to innate and adaptive immune response activation. It has been demonstrated 
that the ligands for TLR9 can inhibit HBV replication in the livers of HBV transgenic mice (19), suggesting that TLR9 plays a role in regulating HBV. In our previous study, we used $\mathrm{CpG}$ as a tool to establish a model of innate immune response to viral molecules, and our data suggested that IFN- $\alpha$ secretion decreased significantly in patients with HBV infection compared to healthy controls. This was compatible with results from other studies $(20,21)$, but these prior data did not account for potential genetic mechanisms underlying the response to the CpG motif. Recognition of these motifs requires TLR9, which induces cell signaling pathways including MAPKs and $\mathrm{NF}-\kappa \mathrm{B}$ (5). In other viral infectious diseases, such as HIV, TLR9 polymorphisms have been found to be associated with the rapid progression of HIV-1 infection (22). For these reasons, we have studied whether such SNPs play a role in susceptibility to HBV.

Mutations in the coding region of several human genes that profoundly affect the protein sequence and influence the course of hepatitis B have been described (23-25). As well, mutations in the promoter region of various genes influence the severity of HBV infection (26). In the present study, we found the TLR9 T-1486C polymorphism to be associated with HBV-related liver cirrhosis. Although the mechanism by which this variant causes variability in the response to TLR9 activation is poorly understood, a role for an endogenous antiviral immune mediator such as TLR9 in liver damage progression seems plausible. Watanabe et al indicated that apoptotic hepatocyte DNA inhibits hepatic stellate cell chemotaxis via TLR9 (27). In HCV infection, Huang et al demonstrated a significant difference between TLR9 gene expression in HCV cirrhosis compared to healthy liver (28). Innate immune responses linked to TLR7, whose activation stimulates the secretion of IFN- $\alpha$, and TLR7 polymorphisms have been shown to be associated with inflammation and fibrosis in chronic HCV infection (18). The innate immune response generates soluble growth factors, cytokines, chemokines and extracellular proteinases, which contribute to early neoplastic development and potentiate tumorigenesis (29). TLRs are important in the innate response to pathogens. TLR9 is detected in CpG-responsive but not unresponsive monocytes (30). Altered responsiveness to viral stimuli on hepatocytes or to immune cells that infiltrate the liver may reduce the amount of damage caused by an antiviral immune response. Consequently, fibrosis and cirrhosis progression would also be delayed. TLR9 activation in the course of HBV infection is therefore a double-edged sword: activation is probably warranted in the setting of acute infection to clear the virus, but is responsible for liver scarring in the setting of chronic disease.

The regulation of innate immune response is genderdependent. This may explain why men are more prone to infections (31), while women are more likely to suffer from autoimmune disease (32). Innate immune responses linked to TLR4 have been shown to differ between men and women, rendering men more susceptible to sepsis or endotoxin shock $(33,34)$. A recent study observed gender differences in IFN- $\alpha$ production by pDCs in response to TLR7 stimulation (35). TLR7 SNPs have been found to offer protection against advanced inflammation and fibrosis in male patients with chronic HCV infection (18). In the present study, we aimed to determine the correlation between the TLR9 polymorphism and gender. However, no associations between this SNP and gender were found.

In summary, we present the first analysis of TLR9 SNPs in patients with chronic HBV infection. Our data suggest that the TLR9 T-1486C polymorphism is associated with the occurence of liver cirrhosis. Knowledge of this polymorphism may have predictive significance in patients with chronic $\mathrm{HBV}$, allowing physicians to use more aggressive therapy in patients with a high risk of disease progression.

\section{Acknowedgements}

This study was supported by grants from the National Natural Science Foundation of China (30671838) and the Committee of Science and Technology of Shanghai Municipal Government (044119624).

\section{References}

1. Fattovich G, Bortolotti F and Donato F: Natural history of chronic hepatitis B: special emphasis on disease progression and prognostic factors. J Hepatol 48: 335-352, 2008.

2. Bataller R, North KE and Brenner DA: Genetic polymorphisms and the progression of liver fibrosis: a critical appraisal. Hepatology 37: 493-503, 2003.

3. Hirose A, Ono M, Saibara T, et al: Angiotensin II type 1 receptor blocker inhibits fibrosis in rat non-alcoholic steatohepatitis. Hepatology 45: 1375-1381, 2007.

4. Xiao F, Wei H, Song S, Li G and Song C: Polymorphisms in the promoter region of the angiotensinogen gene are associated with liver cirrhosis in patients with chronic hepatitis B. J Gastroenterol Hepatol 21: 1488-1491, 2006.

5. Barchet W, Cella M and Colonna M: Plasmacytoid dendritic cells-virus experts of innate immunity. Semin Immunol 17: 253-261, 2005.

6. Szabo G, Dolganiuc A and Mandrekar P: Pattern recognition receptors: a contemporary view on liver diseases. Hepatology 44 : 287-298, 2006.

7. Cooper CL, Davis HL, Morris ML, et al: CPG 7909, an immunostimulatory TLR9 agonist oligodeoxynucleotide, as adjuvant to Engerix-B HBV vaccine in healthy adults: a double-blind phase I/ II study. J Clin Immunol 24: 693-701, 2004.

8. Xu N, Yao HP, Sun Z and Chen Z: Toll-like receptor 7 and 9 expression in peripheral blood mononuclear cells from patients with chronic hepatitis B and related hepatocellular carcinoma. Acta Pharmacol Sin 29: 239-244, 2008.

9. Schroder NW, Diterich I, Zinke A, et al: Heterozygous Arg753Gln polymorphism of human TLR-2 impairs immune activation by Borrelia burgdorferi and protects from late stage Lyme disease. J Immunol 175: 2534-2540, 2005.

10. Texereau J, Chiche JD, Taylor W, Choukroun G, Comba B and Mira JP: The importance of Toll-like receptor 2 polymorphisms in severe infections. Clin Infect Dis 41: S408-S415, 2005.

11. Smirnova I, Mann N, Dols A, et al: Assay of locus-specific genetic load implicates rare Toll-like receptor 4 mutations in meningococcal susceptibility. Proc Natl Acad Sci USA 100: 6075-6080, 2003.

12. Van der Graaf CA, Netea MG, Morre SA, et al: Toll-like receptor 4 Asp299Gly/Thr399Ile polymorphisms are a risk factor for Candida bloodstream infection. Eur Cytokine Netw 17: 29-34, 2006.

13. Agnese DM, Calvano JE, Hahm SJ, et al: Human toll-like receptor 4 mutations but not CD14 polymorphisms are associated with an increased risk of gram-negative infections. J Infect Dis 186: 1522-1525, 2002.

14. Barber RC, Aragaki CC, Rivera-Chavez FA, Purdue GF, Hunt JL and Horton JW: TLR4 and TNF-alpha polymorphisms are associated with an increased risk for severe sepsis following burn injury. J Med Genet 41: 808-813, 2004.

15. Montes AH, Asensi V, Alvarez V, et al: The Toll-like receptor 4 (Asp299Gly) polymorphism is a risk factor for Gram-negative and haematogenous osteomyelitis. Clin Exp Immunol 143: 404-413, 2006. 
16. Tal G, Mandelberg A, Dalal I, et al: Association between common Toll-like receptor 4 mutations and severe respiratory syncytial virus disease. J Infect Dis 189: 2057-2063, 2004.

17. Hawn TR, Verbon A, Lettinga KD, et al: A common dominant TLR5 stop codon polymorphism abolishes flagellin signaling and is associated with susceptibility to Legionnaires' disease. J Exp Med 198: 1563-1572, 2003.

18. Schott E, Witt H, Neumann K, et al: A Toll-like receptor 7 single nucleotide polymorphism protects from advanced inflammation and fibrosis in male patients with chronic HCV-infection. J Hepatol 46: 198-205, 2007.

19. Isogawa M, Robek MD, Furuichi Y and Chisari FV: Toll-like receptor signaling inhibits hepatitis B virus replication in vivo. J Virol 79: 7269-7272, 2005

20. Duan XZ, Wang M, Li HW, Zhuang H, Xu D and Wang FS: Decreased frequency and function of circulating plasmacytoid dendritic cells (pDC) in HBV infected humans. J Clin Immunol 24: 637-646, 2004

21. Van der Molen RG, Sprengers D, Binda RS, et al: Functional impairment of myeloid and plasmacytoid dendritic cells of patients with chronic hepatitis B. Hepatology 40: 738-746, 2004.

22. Bochud P-Y, Hersberger M, Taffe P, et al: Polymorphisms in Toll-like receptor 9 influence the clinical course of HIV-1 infection. AIDS 21: 441-446, 2007.

23. De Andrade DR Jr and De Andrade DR: The influence of the human genome on chronic viral hepatitis outcome. Rev Inst Med Trop Sao Paulo 46: 119-126, 2004.

24. Wang FS: Current status and prospects of studies on human genetic alleles associated with hepatitis B virus infection. World J Gastroenterol 9: 641-644, 2003.

25. Chong WP, To YF, Ip WK, et al: Mannose-binding lectin in chronic hepatitis B virus infection. Hepatology 42: 1037-1045, 2005 .
26. Höhler T, Kruger A, Gerken G, Schneider PM, Meyer zum Büschenefelde $\mathrm{KH}$ and Rittner C: A tumor necrosis factor-alpha (TNF-alpha) promoter polymorphism is associated with chronic hepatitis B infection. Clin Exp Immunol 111: 579-582, 1998.

27. Watanabe A, Hashmi A, Gomes DA, Town T, Badou A, Flavell RA and Mehal WZ: Apoptotic hepatocyte DNA inhibits hepatic stellate cell chemotaxis via toll-like receptor 9. Hepatology 46: 1509-1518, 2007.

28. Huang XX, McCaughan GW, Shackel NA and Gorrell MD: Upregulation of proproliferative genes and the ligand/receptor pair placental growth factor and vascular endothelial growth factor receptor 1 in hepatitis C cirrhosis. Liver Int 27: 960-968, 2007.

29. Coussens LM and Werb Z: Inflammation and cancer. Nature 420: 860-867, 2002.

30. Takeshita F, Leifer CA, Gursel I, et al: Cutting edge: role of tolllike receptor 9 in CpG DNA-induced activation of human cells. J Immunol 167: 3555-3558, 2001.

31. Offner PJ, Moore EE and Biffl WL: Male gender is a risk factor for major infections after surgery. Arch Surg 134: 935-940, 1999.

32. Kast RE: Predominance of autoimmune and rheumatic diseases in females. J Rheumatol 4: 288-292, 1977.

33. Marriott I, Bost KL and Huet-Hudson YM: Sexual dimorphism in expression of receptors for bacterial lipopolysaccharides in murine macrophages: a possible mechanism for gender-based differences in endotoxic shock susceptibility. J Reprod Immunol 71: 12-27, 2006.

34. Imahara SD, Jelacic S, Junker CE and O'Keefe GE: The influence of gender on human innate immunity. Surgery 138: 275-282, 2005.

35. Berghofer B, Frommer T, Haley G, Fink L, Bein G and Hackstein H: TLR7 ligands induce higher IFN-alpha production in females. J Immunol 177: 2088-2096, 2006. 